\title{
Publisher Correction: Expanding the social science of happiness
}

John F. Helliwell (D) and Lara B. Aknin

Correction to: Nature Human Behaviour https://doi.org/10.1038/s41562-018-0308-5, published online 26 February 2018.

In the version of this Perspective originally published, both authors were incorrectly indicated as being at both affiliations 1 and 2 . However, John F. Helliwell is only affiliated with the ${ }^{1}$ University of British Columbia and Lara B. Aknin is only affiliated with ${ }^{2}$ Simon Fraser University. This has now been corrected. 